\title{
A Comparison of Satellite-Derived, Low-Level and Cirrus-Level Winds with Conventional Wind Observations
}

\author{
Kenneth O. Poteat \\ National Environmental Satellite Service, SFSS, Miami, Fla. 33124
}

6 June 1973 and 4 September 1973

\begin{abstract}
The suitability of satellite-derived, low-level and cirrus-level winds for application to operational weather analyses in low latitudes is established. It is shown that satellite-derived, low-level winds compare very favorably with conventional data near the gradient level, and somewhat more favorably with 2000-ft than with $850-\mathrm{mb}$ winds. Satellite-derived, cirrus-level winds compared favorably with 200 -mb data.
\end{abstract}

\section{Introduction}

The primary purpose of this study was to determine the suitability of satellite-derived cloud motions (winds) for use as data on meteorological charts in the tropics. More specifically, the study was designed to establish the suitability of 1) satellite-derived, low-level winds for use on the Analysis of the Tropical Oceanic Lower Layer (ATOLL) chart prepared by the Regional Center for Tropical Meteorology (RCTM) at the National Furricane Center (NHC), Miami, Fla., and 2) satellite- derived, cirrus-level winds for use at the 200-mb level, also prepared at the RCTM.

One factor which contributes to uncertainty in wind determinations made from Applications Technology Satellite (ATS) pictures is the unknown height of target clouds. This was discussed by Gaby and Poteat (1973) and previously by others. However, the motions of low-level and cirrus-level clouds as observed in timelapse film loops constructed from photographs by the geostationary Applications Technology Satellite 3 


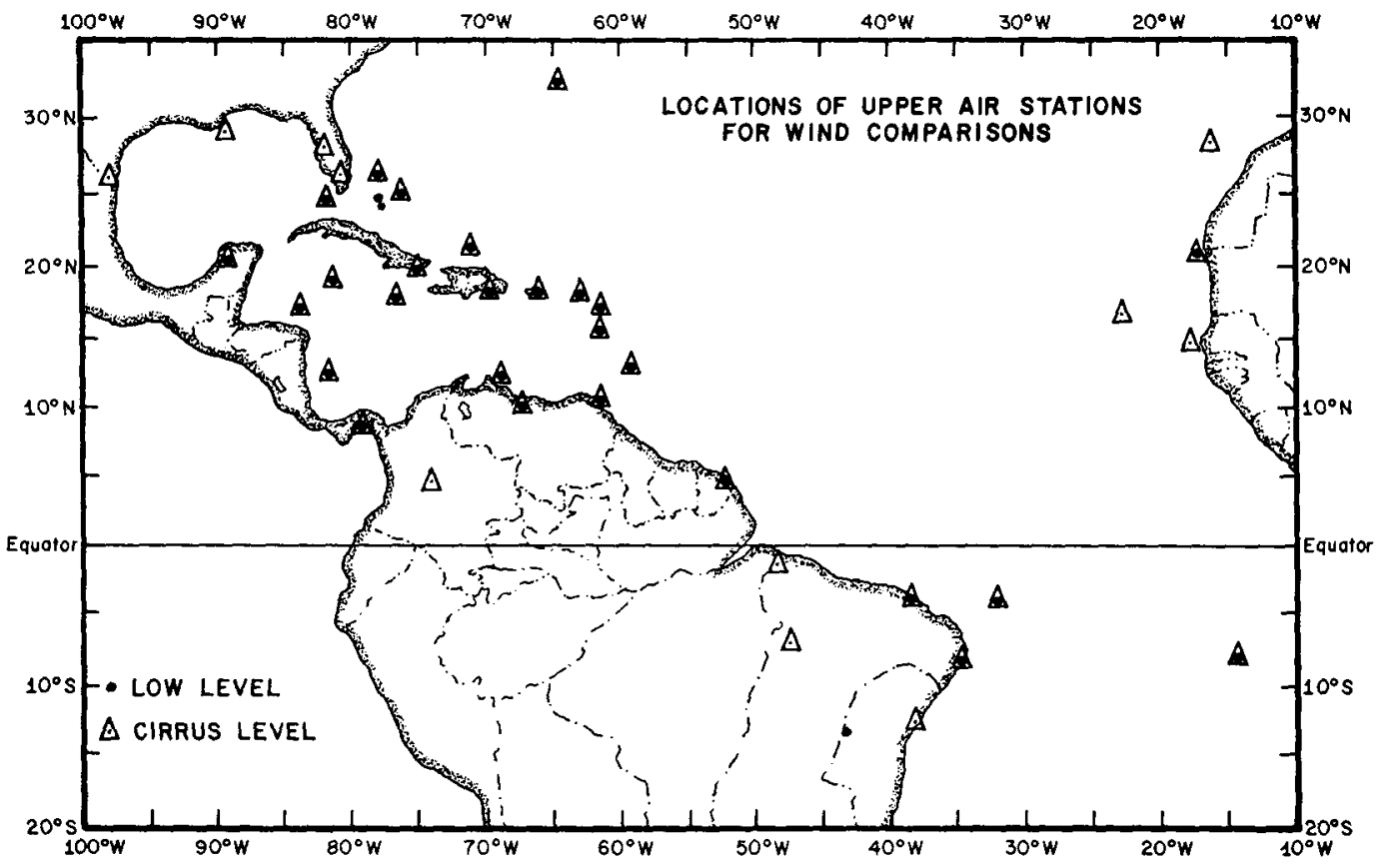

FIg. 1. Locations of upper air stations used for wind comparisons.

(ATS 3), determined using Fujita's (1969) methods, have been used to supplement conventionally observed winds in data-void tropical regions of the Atlantic and Eastern Pacific Oceans. The climatology of these satellite-derived winds has been studied by Gaby and Poteat (1973). Other studies-Hubert and Whitney (1971) and Serebreny et al. (1969)-have shown that low-cloud motions correspond well with conventionally observed winds at about the $3000-\mathrm{ft}$ level, and cirrus cloud motions compare best with winds at the $30,000-\mathrm{ft}$ level for their total sample. However, the comparison levels of the present study are the $2000-\mathrm{ft}$, the $850-\mathrm{mb}$, and the 200-mb levels. These cloud level comparisons were made to correspond to the charts which are available at the NHC.

\section{Procedure}

An ellipse having a major axis of $4^{\circ}$ of latitude and a minor axis of $2^{\circ}$ of latitude was used to determine the eligibility of satellite-derived winds for comparison
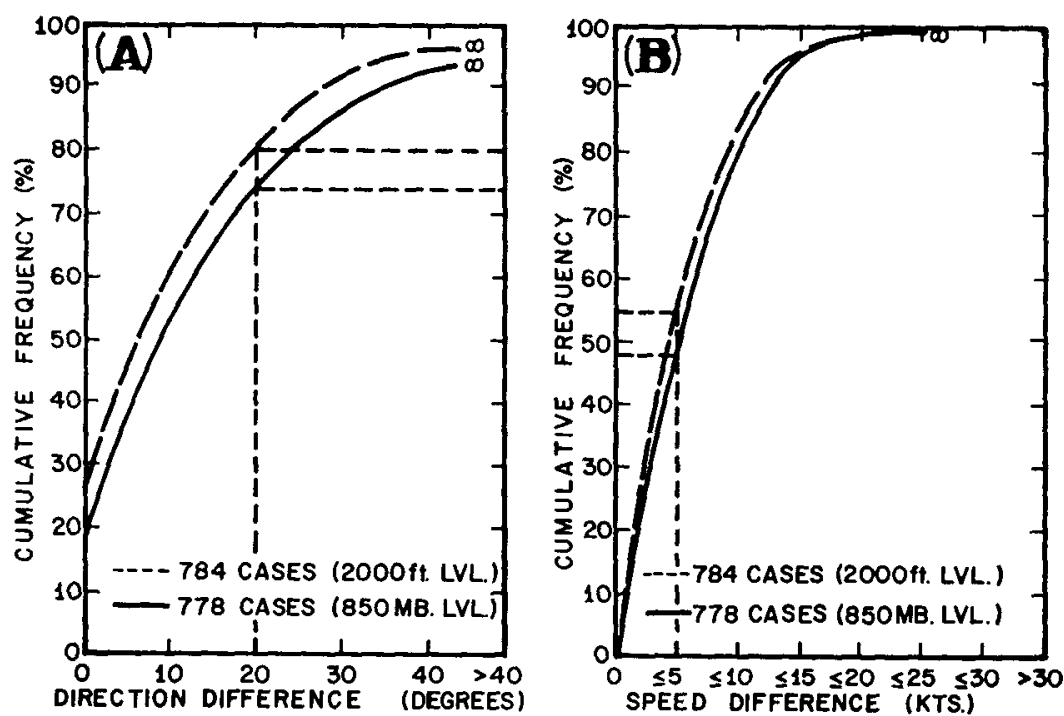

FIG. 2. Cumulative frequency distribution of differences in wind direction (A) and wind speed $(B)$ between satellite-derived, low-level winds and conventionally observed values. 

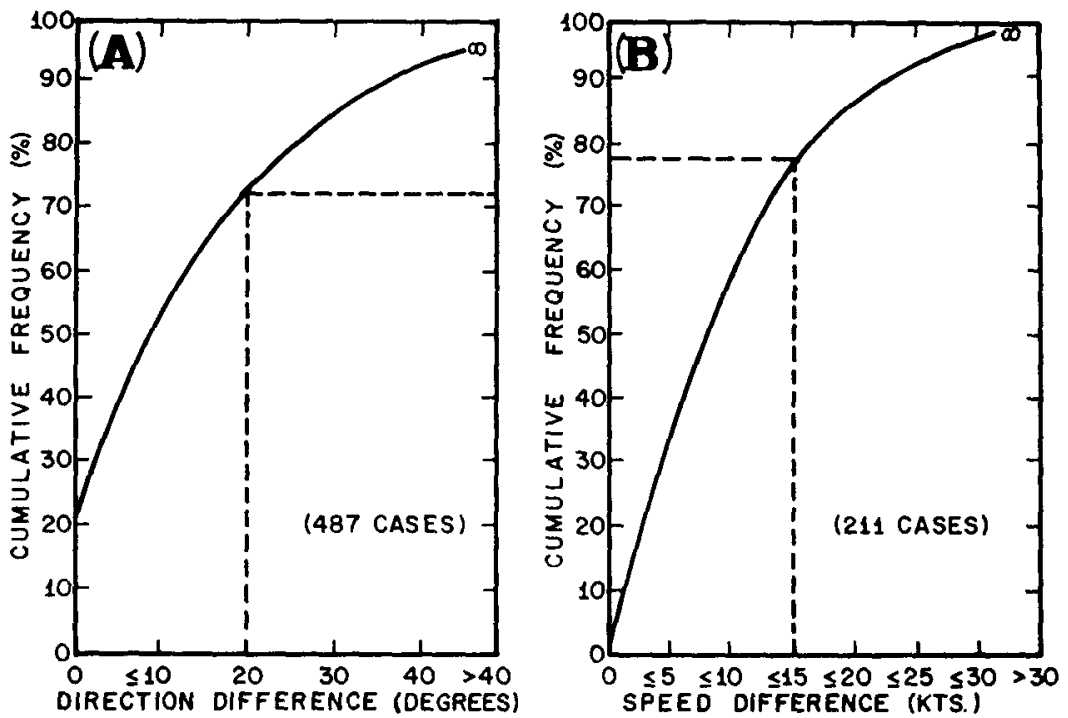

Fig. 3. Cumulative frequency distributions of differences in wind direction (A) and wind speed (B) between satellite-derived, cirrus-level winds and conventionally observed values.

with conventional observations. A plastic tool bearing the ellipse was placed over a rawinsonde/pibal station with the major axis of the ellipse aligned parallel with the plotted wind. Whenever a cloud displacement vector (wind), at either low level or cirrus level, fell at least partly within the ellipse, comparison was made with the observed wind at $2000 \mathrm{ft}$ and/or $850 \mathrm{mb}$ or at 200 $\mathrm{mb}$.

The upper air stations used for comparison of the low-level and cirrus-level vectors with conventional wind observations are shown in Fig. 1.

These comparisons cover a 10 -month period from October 1970 through July 1971. The comparisons were made for manually corrected ATS 3 satellite-derived winds (Gaby and Poteat, 1973) when diurnal motion of the satellite was small. All comparisons were made between 1200 GMT charts and satellite winds derived from movie loops over the period 1200-1600 GMT. The low-cloud data sample consisted of 784 cases for the $2000-\mathrm{ft}$ level and 778 cases for the $850-\mathrm{mb}$ level. For the cirrus level, the data sample consisted of 487 cases for wind direction comparison and 211 cases for wind speed comparison. The larger number of cases for direction comparison indicated that satellite-derived speed could not be determined at all times. Frequently, no specific characteristic of the cirrus clouds could be identified through the period which is used for cloud motion determination.

\section{Results}

Satellite-ATOLL $(2000 \mathrm{ft})$ and satellite- $850 \mathrm{mb}$ comparisons are illustrated in the graphs of Fig. 2, which show differences in wind direction and wind speed versus cumulative percent frequency. Significant points to be made are:
1) For direction, $80 \%$ of the cases were within $20^{\circ}$ of the 2000-ft winds compared with $74 \%$ at $850 \mathrm{mb}$.

2) For speed, $55 \%$ of the cases were within $5 \mathrm{kt}$ of the $2000-\mathrm{ft}$ winds compared with $49 \%$ at $850 \mathrm{mb}$.

Cirrus vs $200-\mathrm{mb}$ comparisons are presented in the graphs of Fig. 3, which show differences in wind direction and wind speed versus cumulative percent frequency. The most significant points to be noted are:

1) For direction, $73 \%$ of the cases were within $20^{\circ}$ of the 200-mb wind.

2) For speed, $78 \%$ of the cases were within $15 \mathrm{kt}$ of the 200 -mb wind.

\section{Conclusion}

Satellite-derived, low-level winds compare somewhat more favorably with those at the 2000-ft level than with those at the $850-\mathrm{mb}$ level, but the difference is small. These data appear well suited for use on the ATOLL charts. They probably are almost as suitable for use on the 1000 to $600 \mathrm{mb}$ mean low level flow chart of the NHC.

The methods employed for deriving cirrus-level winds from ATS 3 movie loops provide a satisfactory data input at the $200-\mathrm{mb}$ level for large areas where there are no other observations.

Acknowledgments. The author is grateful for the encouragement of Dr. Robert H. Simpson and Mr. Donald C. Gaby. Appreciation is extended to Mr. J. J. Fernandez-Partagas for his many helpful suggestions and to Prof. M. A. Estoque for review of the manuscript. Thanks are also due Mr. R. L. Carrodus for preparing the figures and Mrs. Frances Humphreys for typing the manuscript. 


\section{REFERENCES}

Fujita, T., 1969: Present status of cloud velocity computations from the ATS-1 and ATS-3 satellites. Space Research $I X$, Amsterdam, North Holland Publ. Co., 557-570.

Gaby, D. C., and K. O. Poteat, 1973: ATS-3 satellite-derived low-level winds: A provisional climatology. J. A ppl. Metent., $12,1054-1061$.
Hubert, L. F., and L. F. Whitney, Jr., 1971: Wind estimation from geostationary satellite pictures. Mon. Wea. Rev., 99, $665-672$.

Serebreny, S. M., R. G. Hadfield, R. M. Trudeau and E. J. Wiegman, 1969: Comparison of cloud motion vectors and rawinsonde data. Report, Stanford Research Institute, Menlo Park, Calif., 57 pp. 